\title{
Granuloma eosinofílico orbitário
}

\author{
Orbital eosinophilic granuloma
}

\author{
Eduardo Ferrari Marback ${ }^{1}$ \\ Roberto Deway Guimarães ${ }^{2}$ \\ Manuella Nader ${ }^{3}$ \\ Lívia Maria Nossa Moitinho ${ }^{4}$ \\ Roberto Lorens Marback ${ }^{5}$
}

\begin{tabular}{|l|}
\hline RESUMO \\
\hline Objetivo: Relatar, de forma retrospectiva, a experiência no diagnóstico e \\
tratamento do granuloma eosinofílico da órbita em serviço de referência. \\
Métodos: Identificados os pacientes com diagnóstico de granuloma eosi- \\
nofílico orbitário, no Registro do Laboratório de Patologia Ocular do \\
Hospital Universitário Professor Edgard Santos, Universidade Federal da \\
Bahia, no período entre 1974 e 2004. Coletados dados referentes ao \\
diagnóstico, tratamento e realizada revisão das lâminas coradas pela \\
hematoxilina e eosina. Resultados: Foramidentificados 3 casos comidade \\
de 1,6e 11 anos. Em nenhum caso o diagnóstico de granuloma eosinofílico \\
foi aventado pré-operatoriamente. Todos pacientes foram submetidos a \\
biópsia, exibindo aspecto anatomopatológico típico. Em um dos casos, \\
após a biópsia, havia tomografia computadorizada da órbita disponível, \\
exibindo padrão característico. Todos os pacientes foram tratados com \\
corticoesteróides sistêmicos, com resolução do tumor orbitário. Conclu- \\
são: Trata-se de doença rara, de difícil diagnóstico clínico sem avaliação \\
radiológica. Apesar da grande destruição tecidual, apresenta boa resposta \\
ao tratamento com corticoesteróides.
\end{tabular}

Descritores: Histiocitose de células de Langerhans/diagnóstico; Histiocitose de células de Langerhans/quimioterapia; Histiocitose de células de Langerhans/patologia; Órbita/lesões; Doenças orbitárias; Granuloma eosinófilo; Corticosteróides/uso terapêutico

Trabalho realizado no Hospital Universitário Professor Edgard Santos, Universidade Federal da Bahia - UFBA - Salvador (BA) - Brasil.

${ }^{1}$ Oftalmologista do Hospital Universitário Prof. Edgard Santos, Faculdade de Medicina da Universidade Federal da Bahia - UFBA - Salvador (BA) - Brasil e do Hospital São Rafael, Fundação Monte Tabor - Salvador (BA) - Brasil.

${ }^{2}$ Médico Colaborador do Serviço de Oftalmologia do Hospital Universitário Prof. Edgard Santos, Faculdade de Medicina da UFBA - Salvador (BA) - Brasil.

${ }^{3}$ Aluna do Curso de Especialização em Oftalmologia da Faculdade de Medicina da UFBA - Salvador (BA) Brasil.

${ }^{4}$ Médica Colaboradora do Serviço de Oftalmologia do Hospital Universitário Prof. Edgard Santos, Faculdade de Medicina da UFBA - Salvador (BA) - Brasil.

${ }^{5}$ Professor Titular de Oftalmologia da Faculdade de Medicina da UFBA - Salvador (BA) - Brasil. Chefe do Serviço de Oftalmologia do Hospital São Rafael, Fundação Monte Tabor - Salvador (BA) - Brasil.

Endereço para correspondência: Eduardo F. Marback. Rua Eduardo José dos Santos, 147 - Sala 808 - Salvador (BA) CEP 41940-455

E-mail: eduardomarback@ufba.br

Recebido para publicação em 24.12.2005

Última versão recebida em 25.11.2007

Aprovação em 15.01.2008

\footnotetext{
INTRODUÇÃO

A histiocitose de células de Langerhans (HCL) é um grupo de doenças com mesmo padrão histológico e manifestação clínica variada ${ }^{(1)}$. Assim, as doenças antes conhecidas como histiocitoses $\mathrm{X}$ passam a ser classificados como HCL aguda e disseminada (doença de Letterer-Siwe); HCL mutifocal (doença de Hand-Schüller-Christian) e HCL unifocal (granuloma eosinofílico $)^{(1-3)}$. Apesar da grande evolução no entendimento de sua fisiopatologia, o melhor esquema terapêutico ainda é bastante discutido variando de acordo com a forma de apresentação e evolução de cada caso ${ }^{(1-4)}$.

A órbita pode ser acometida de forma secundária nos subtipos da doença multifocal ou como foco único e isolado. $O$ granuloma eosinofílico orbitário tipicamente acomete crianças e adolescentes do sexo masculino, apresenta crescimento rápido, aspecto inflamatório e grande destruição tecidual, que contrasta com sua natureza benigna ${ }^{(1-3)}$. Esta forma de apresentação e a raridade da doença, freqüentemente causam erros no diagnóstico clínico da lesão ${ }^{(1-3,5)}$.

O objetivo deste trabalho é relatar, de forma retrospectiva, a nossa experiência com três casos de granuloma eosinofílico orbitário, discutindo seus aspectos clínicos, a dificuldade diagnóstica e revisando seu aspecto histopatológico.
} 


\section{MÉTODOS}

O Registro do Laboratório de Patologia Ocular do Hospital Universitário Professor Edgard Santos, Universidade Federal da Bahia, foi pesquisado para identificar os casos de HCL tratados por nós e submetidos para estudo entre os anos de 1974 e 2004. Três casos foram identificados nos anos de 1978, 1981 e 2004 respectivamente. O caso de 1978 foi excluído, pois havia também outras lesões líticas em calota craniana bem como hepatomegalia caracterizando-o como doença de HandSchüller-Christian. Adicionalmente, um caso tratado pelos autores no ano de 1998, no Hospital São Rafael, Fundação Monte Tabor, Salvador-Bahia, foi incluído. Os prontuários foram revisados sendo anotados dados referentes ao gênero, idade, tempo de sintomatologia, aspecto, localização, suspeita diagnóstica inicial, tratamento e revisão das lâminas coradas pela hematoxilina e eosina.

\section{RESULTADOS}

Todos os pacientes eram do sexo masculino. Com idades de 1 , 6 e 11 anos. Os casos 1 e 3 se apresentaram com massa de aspecto inflamatório em ângulo súpero-externo da órbita esquerda com crescimento relativamente rápido (Quadro 1). O caso 2 apresentava massa palpável nesta região, porém exibia também proptose (Figura 1). O caso 1, apesar da história de massa com aspecto inflamatório há trinta dias, foi vítima de queda no dia anterior ao internamento com aumento significativo do volume da lesão por hematoma comprovado durante a biópsia.

A suspeita diagnóstica inicial foi de tumor orbitário a esclarecer no caso 1 e rabdomiossarcoma no caso 2 . O caso 3, antes de ser avaliado pelos autores, havia sido tratado como celulite orbitária em outro serviço com amoxicilina e metronidazol por 14 dias, sem melhora (Figura 2). Foi internado no Hospital Universitário Prof. Edgard Santos, com suspeita de celulite orbitária não responsiva ao tratamento clínico por suposto abscesso, para ser submetido a drenagem. Durante o ato cirúrgico, como não foi encontrada nenhuma coleção, um fragmento de tecido foi removido para estudo anatomopatológico e então solicitada nossa avaliação (Quadro 1).

A acuidade visual (AV), não estava comprometida ao exame inicial nos casos 1 e 3 . O caso 2 apresentava AV diminuída para conta dedos. Esta baixa de AV foi atribuída a ceratite de exposição pela intensa proptose, havendo recuperação da AV normal após o tratamento.
Febre foi relatada pelos familiares no caso 3 antes da admissão. Durante o período de internação nenhum pico de hipertermia foi registrado em nenhum dos casos.

Todos os pacientes foram submetidos a biópsia incisional. As lâminas coradas pela hematoxilina e eosina exibiam infiltrado inflamatório do tipo granulomatoso, com múltiplas células gigantes multi-nucleadas tipo Langerhans. Infiltração maciça de eosinófilos foi vista apenas no caso 1, com presença bem menos pronunciada para os casos 2 e 3 (Figura 3). Em todos os casos foram feitas colorações para afastar a possibilidade de infecção fúngica ou por micobactéria (Grocott e Ziehl). No caso 3, foi feita reação imunohistoquímica com positividade para proteína S-100.

Não havia nos registros médicos, informações sobre o aspecto radiológico para os casos 1 e 2 . O caso 3 apresentava tomografia das órbitas, realizada após a biópsia, mostrando massa com densidade de partes moles em ângulo súperoexterno da órbita esquerda e erosão de osso frontal. O defeito ósseo no rebordo orbitário era identificado também na radiografia simples da órbita. Logo após o tratamento, tal defeito era visível ao exame externo (Figura 2).

Após o diagnóstico anatomopatológico, todos os pacientes foram encaminhados para avaliação pediátrica e, apesar da ausência de focos múltiplos da doença, tratados com prednisona via oral, em dose inicial de $1 \mathrm{mg} / \mathrm{kg}$ com retirada gradual que variou de 1 a 4 meses (Figuras 1 e 2). Nenhum dos casos apresentou recidiva durante o período de acompanhamento (Quadro 1).

\section{DISCUSSÃO}

O acometimento orbitário na HCL é raro. Em sua série de 1.795 tumores orbitários coletados durante 50 anos, Garrity, Henderson e Cameron encontraram apenas 12 casos $(0,67 \%)$, sendo que em pelo menos seis destes a doença era multifocal ${ }^{(6)}$. Devido à raridade e apresentação com características inflamatórias, erros no diagnóstico clínico são freqüentes. Os diagnósticos clínicos mais freqüentemente aventados são celulite orbitária, cisto dermóide, tumores metastáticos e tumores epiteliais da glândula lacrimal ${ }^{(1-3,5)}$. Ao nosso ver, tais erros são especialmente propensos a ocorrer quando não existe estudo tomográfico prévio à biópsia, como em todos os nossos casos. O achado de massa com destruição óssea na órbita de uma criança, com lesão que clinicamente demonstra sinais inflamatórios é muito sugestivo do diagnóstico de $\mathrm{HCL}^{(2-3)}$. Este

\begin{tabular}{|c|c|c|c|c|c|c|}
\hline \multicolumn{7}{|c|}{ Quadro 1. Características dos pacientes } \\
\hline Caso & Gênero & Idade * & Tempo ** & Relato de febre & Suspeita & Seguimento \\
\hline 1 & $\mathrm{M}$ & 1 & 30 & Ausente & Tumor orbitário & 9 meses \\
\hline 2 & M & 11 & 60 & Ausente & Rabdomiossarcoma & 7 anos \\
\hline 3 & M & 6 & 20 & 1 episódio & $\star \star \star ~$ & 9 meses \\
\hline
\end{tabular}




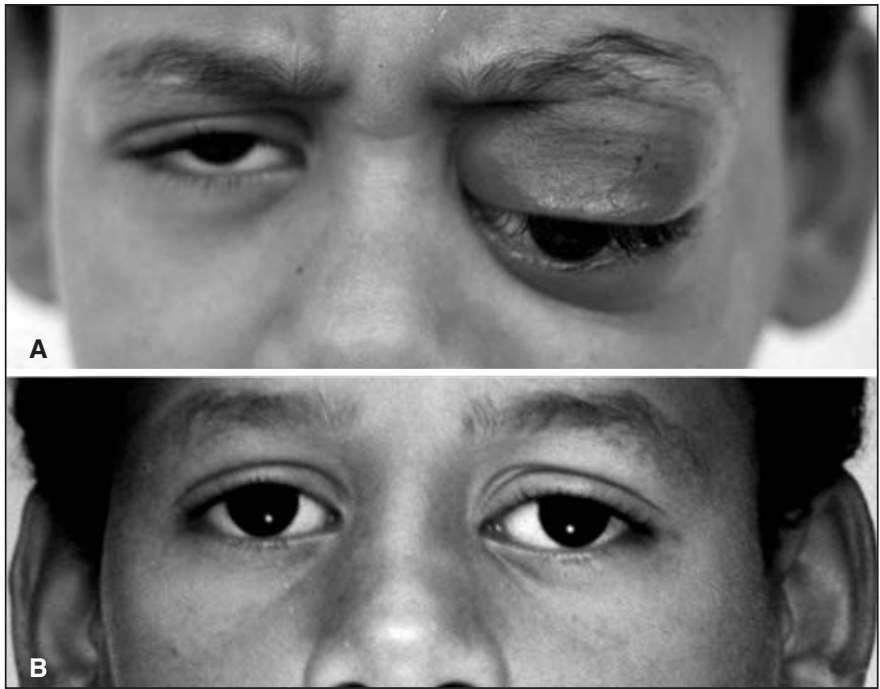

Figura 1 - Caso 2: A) Proptose à esquerda com desvio inferior; B) Resolução do quadro após o tratamento com corticosteróide sistêmico aspecto radiológico pode ser visto também em tumores epiteliais malignos de glândula lacrimal e em lesões metastáticas, ambos muito raros na infância, sendo o diagnóstico geralmente feito após biópsia ou, nos casos de lesão metastática, ao se encontrar o sítio primário na investigação diagnóstica pré-operatória ${ }^{(1-3)}$. Já nos casos de celulite orbitária diferenciase da HCL pois usualmente pode apresentar prostração, oftalmoplegia e imagem sugestiva de sinusite nos exames de imagem. Em relação ao cisto dermóide, este seria um diagnóstico diferencial mais freqüente quando se dispunha apenas da radiografia simples, uma vez que à tomografia computadorizada as lesões apresentam aspecto totalmente diverso.

Os avanços no entendimento da fisiopatologia da HCL, explicam algumas das características do granuloma eosinofílico orbitário $^{(3)}$. A célula que dá origem à lesão parece ser um precursor pluripotencial presente na medula óssea que preserva atividade hematopoiética. Tal célula precursora sofreria transformação em célula de Langerhans patológica devido a

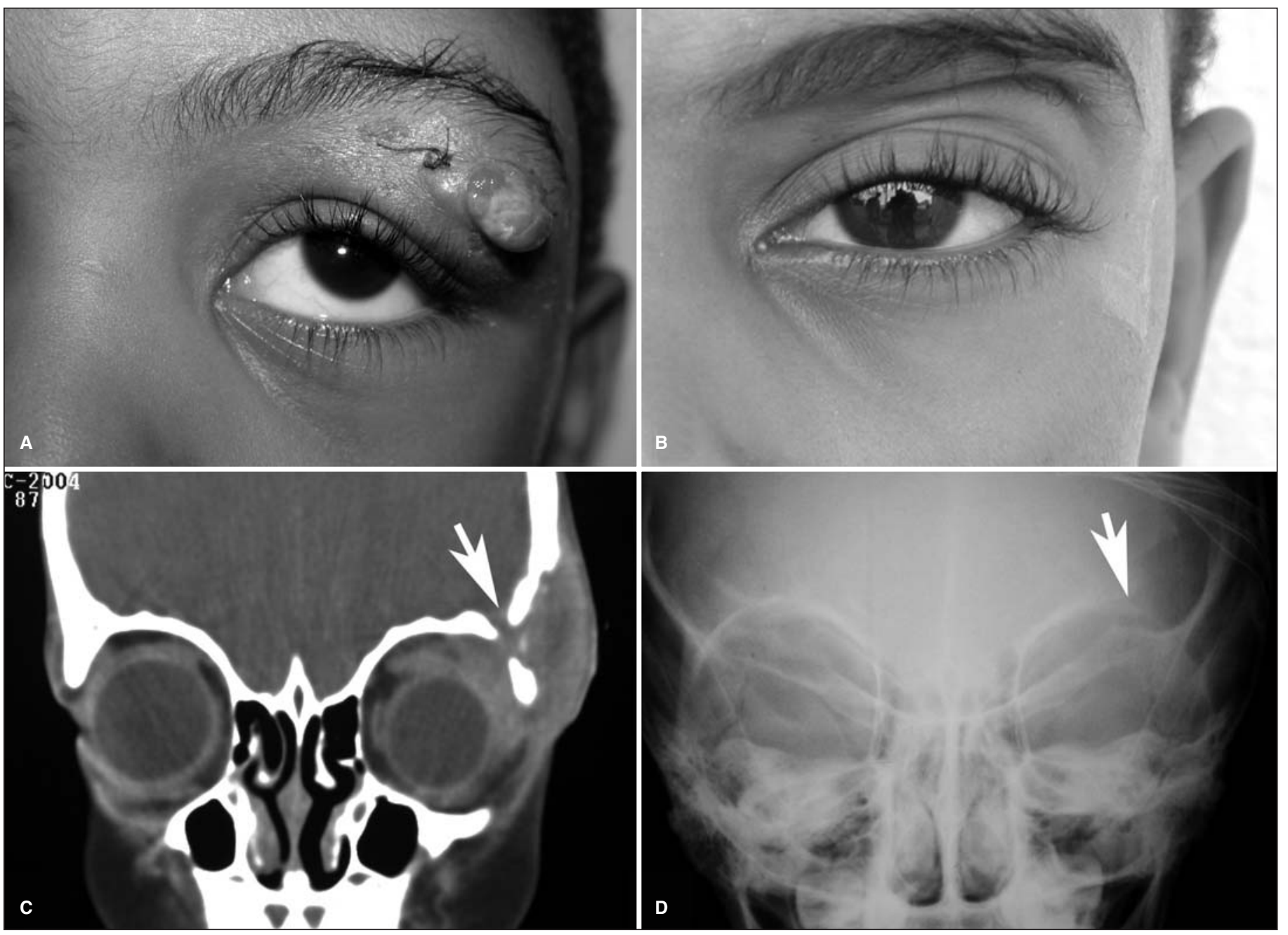

Figura 2 - Caso 3: A) Após tentativa de drenar suposto abscesso orbitário exibindo quadro inflamatório e deiscência de sutura; B) Imediatamente após fim do tratamento com corticosteróide; C) Tomografia computadorizada mostrando lesão lítica de teto orbitário e comunicação com a cavidade craniana (seta); D) Radiografia simples evidencia defeito no contorno do rebordo orbitário esquerdo (seta) 


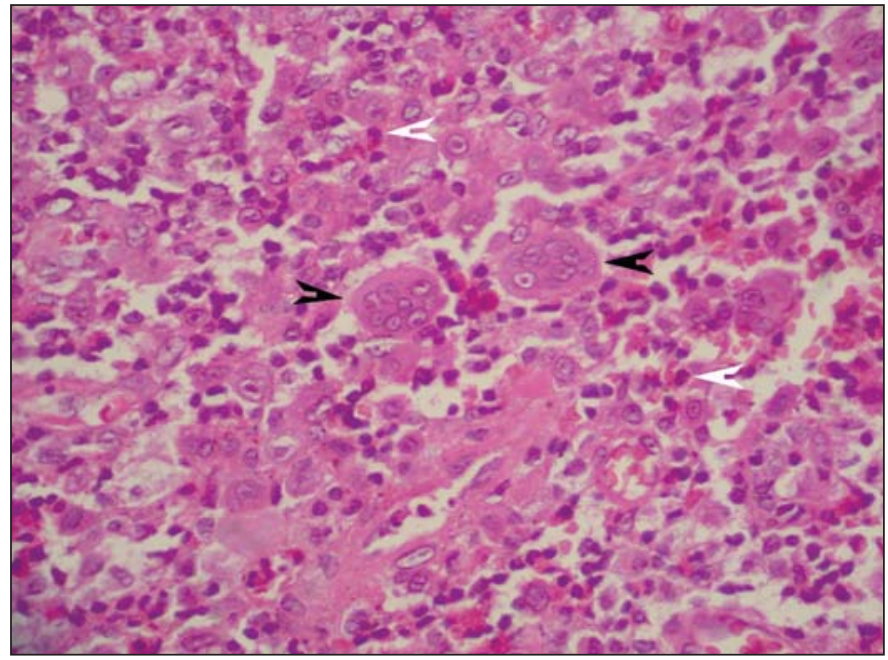

Figura 3 - Caso 3. Aspecto microscópico revela infiltrado inflamatório, composto predominantemente por histiócitos (células de Langerhans). Nota-se a presença de múltiplas células gigantes multi-nucleadas (pontas de seta negras) e alguns eosinófilos à hematoxilina-eosina (pontas de seta brancas).

uma disfunção imune, a duração desta disfunção imune é que explicaria as diferentes formas da doença. Desta forma, uma disfunção temporária como uma infecção viral, poderia levar ao granuloma eosinofílico do osso, enquanto que uma imunodeficiência mais prolongada, como linfoma, leucemia ou mielodisplasia, levaria às formas disseminadas e letais da $\mathrm{HCL}^{(3,7)}$. $\mathrm{Na}$ órbita, cedo na infância, a medula óssea do zigoma e maxilar perde sua capacidade de hematopoiese. Já a medula óssea do frontal, preserva esta capacidade até a vida adulta, ocorrendo um deslocamento lateral à medida em que o seio frontal se expande. Este fato justifica a localização preferencial do granuloma eosinofílico da órbita pela porção lateral do osso frontal ${ }^{(3)}$.

Também a exuberante destruição óssea, tão evidente no granuloma eosinofílico da órbita, parece ser explicada pela produção em grande quantidade de interleucina 1 (IL-1) e prostagladina $\mathrm{E}_{2}\left(\mathrm{PGE}_{2}\right)$ pelas células de Langerhans patológicas. Sabe-se que a IL-1 é uma citocina com grande potencial para a ativação osteoclastos e inibição de osteosíntese, enquanto a $\mathrm{PGE}_{2}$ demonstra in vitro ser indutora da reabsorção óssea ${ }^{(3)}$.

O tratamento do granuloma eosinofílico da órbita é outro assunto no qual inúmeras dúvidas persistem. As opções variam desde nenhum tratamento, até quimioterapia e radioterapia, passando pela simples biópsia da lesão, curetagem do osso acometido, excisão em bloco, injeção intralesional de corticóides e combinação de modalidades ${ }^{(1-10)}$. Nos últimos anos, tem havido uma predileção por inicialmente tentar apenas a biópsia incisional e, quando existe diagnóstico por biópsia de congelamento disponível, combiná-la com a curetagem óssea ou injeção intralesional de corticosteróide ${ }^{(2-6,8)}$. É evidente que as opções nas quais o tratamento limita-se ao ato cirúrgico, possuem menos potencial de efeitos indesejáveis. Entretanto vale lembrar, que ao fazer a biópsia ou a curetagem é importante não remover grande quantidade do periósteo sob pena da reconstituição óssea ser incompleta ${ }^{(1)}$. O prognóstico para o granuloma eosinofílico da órbita é muito bom, entretanto em um terço dos casos pode haver recidiva local ou evolução para outra forma de HCL com o acometimento de outros órgãos ${ }^{(2-4,9-10)}$. Quando a lesão recorrente é também focal, se os sintomas forem leves, pode-se manter apenas conduta expectante, já se o paciente for muito sintomático ou se houver risco de comprometimento cosmético pela grande destruição óssea, pode-se optar pela injeção intralesional de corticosteróides, radioterapia, terapia sistêmica com corticóide isolado ou em associação a outros quimioterápicos. Em relação à esta última opção, embora alguns autores achem que haveria apenas aumento dos efeitos adversos sem benefício adicional ${ }^{(10)}$, outros defendem seu uso com o objetivo de diminuir recorrências ${ }^{(4)}$. Todos os nossos casos foram tratados com corticoesteróides sistêmicos, com acompanhamento por pediatra. Uma vez que nossos três pacientes apresentavam doença óssea unifocal, tal tratamento poderia ser questionado como sendo um excesso. A justificativa para seu uso é que alguns dos nossos pacientes abandonam o acompanhamento precocemente devido a dificuldades socioeconômicas para retornar ao Hospital Universitário, como nos casos 1 e 3, desta forma realizando o tratamento sistêmico esperamos poder contribuir para o não aparecimento de lesões multifocais, embora isto não seja com$\operatorname{provado}^{(7,9-10)}$.

O quadro anatomopatológico típico é de infiltrado inflamatório granulomatoso, composto por células de Langerhans (histiócitos grandes, poliédricos, com citoplasma abundante e mal delimitado, núcleo grande, eventualmente exibindo nucléolo evidente), células gigantes multinucleadas e quantidades variáveis de eosinófilos. É importante a realização de colorações especiais para afastar a possibilidade de processo infeccioso, especialmente em nosso meio. Apesar do granuloma eosinofílico da órbita não ser uma neoplasia, estudos mostram que o infiltrado inflamatório é monoclonal ${ }^{(1,3)}$. Classicamente a lesão exibe ao estudo pela microscopia eletrônica a presença de granulações no citoplasma das células de Langerhans, conhecidas como grânulos de Birbek ${ }^{(1)}$. À imunohistoquímica, as células de Langerhans patológicas exibem positividade para a proteína S-100, e CD1, como a linhagem normal de histiócitos dendríticos apresentadores de antígenos ${ }^{(3)}$.

Em suma, o granuloma eosinofílico da órbita é uma doença rara, de difícil diagnóstico clínico, facilmente confundido com outras afecções orbitárias de origem infecciosa ou neoplásica, especialmente se não houver estudo tomográfico disponível ${ }^{(1-3,5)}$. Paradoxalmente, apresenta grande destruição tecidual e bom prognóstico com tratamento minimamente agressivo ${ }^{(2-7,10)}$.

\section{CONCLUSÃO}

Existem múltiplas opões terapêuticas, incluindo cirurgia, corticóide local ou sistêmico, e outros quimioterápicos, não havendo consenso sobre qual o tratamento ideal. Apesar do prognóstico favorável, é necessário o acompanhamento a lon- 
go prazo dos pacientes acometidos, pelo risco do aparecimento de doença recidivante ou evolução para formas mais agressivas de HCL com comprometimento de múltiplos órgãos.

\section{ABSTRACT}

Purpose: To report the retrospective experience of a reference center in the diagnosis and treatment of orbital eosinophilic granuloma. Methods: A review of the files in the Opththalmic Pathology Laboratory, of the Hospital Universitário Professor Edgard Santos, Universidade Federal da Bahia, between 1974 and 2004, was conducted to identify cases of orbital eosinophilic granuloma. Data of diagnosis and treatment were collected. The hematoxilin and eosin stained sections were reviewed. Results: Three cases with ages of 1, 6 and 11 years were retrieved. In none of them the clinical diagnosis of eosinophilic granuloma was suspected. All patients underwent diagnostic biopsy with characteristic histological aspect. In one case a orbital computed tomography after biopsy exhibited typical findings. All patients improved with systemic steroids. Conclusions: This is a rare disease, with a difficult clinical diagnosis if radiological evaluation is not available. In spite of its aggressiveness at presentation, the disease shows good response to systemic steroids.

Keywords: Histiocytosis, Langerhans-cell/diagnosis; Histiocytosis, Langerhans-cell/treatment; Histiocytosis, Langer- hans-cell/pathology; Orbit/injuries; Orbital diseases; Eosinophilic granuloma; Adrenal cortex hormones/therapeutic use

\section{REFERÊNCIAS}

1. Jakobiec FA, Trokel SL, Aron-Rosa D, Iwamoto T, Doyon D. Localized eosinophilic granuloma (Langerhans' cell histiocytosis) of the orbital frontal bone. Arch Ophthalmol. 1980;98(10):1814-20.

2. Moore AT, Pritchard J, Taylor DS. Histiocytosis X: an ophthalmological review. Br J Ophthalmol. 1985;69(1):7-14.

3. Woo KI, Harris GJ. Eosinophilic granuloma of the orbit: understanding the paradox of aggressive destruction responsive to minimal intervention. Ophthal Plast Reconstr Surg.2003;19(6):429-39.

4. Arceci RJ, Brenner MK, Pritchard J. Controversies and new approaches to treatment of Langerhans cell histiocytosis. Hematol Oncol Clin North Am. 1998;12(2):339-57.

5. Paula JS, Chahud F, Cruz AA. Remissão espontânea de um granuloma eosinofílico orbitário após biópsia: relato de caso e revisão da literatura. Arq Bras Oftalmol. 2003;66(4):523-6

6. Garrity JA, Henderson JW, Cameron JD. Henderson's orbital tumors. 4th ed. New York: Lippincott Williams \& Wilkins; 2007. Chapter 14; Histiocytic disorders. p.267-77.

7. Zelger B. Langerhans cell histiocytosis: a reactive or neoplastic disorder? Med Pediatr Oncol. 2001;37(6):543-4. Comment in: Med Pediatr Oncol. 2001;37(6):545. Comment on: Méd Pediatr Oncol. 2000;35(4):421-5; Méd Pediatr Oncol. 2000;35(4):426-7.

8. Cortes M, Paves L, Nakanami DM, Wolosker AM, Manso PG. Histiocitose de células de Langerhans na órbita: relato de um caso. Arq Bras Oftalmol. 1995;58(6):473-6.

9. Song A, Johnson TE, Dubovy SR, Toledano S. Treatment of recurrent eosinophilic granuloma with systemic therapy. Ophthal Plast Reconstr Surg. 2003:19(2):140-4

10. Broadbent V, Gadner H. Current therapy for Langerhans cell histiocytosis. Hematol Oncol Clin North Am. 1998;12(2):327-38. 